\title{
Fatores de Risco para Violência Contra a Mulher no Contexto Doméstico e Coletivo
}

\section{Risk Factors for Violence Against Women in the Domestic and Collective Contexts}

Luiza Jane Eyre de Souza Vieira

Enfermeira. Doutora em Enfermagem. Professora Titular do Centro de Ciências da Saúde e do Mestrado em Saúde Coletiva, Universidade de Fortaleza. Instituto Dr. José Frota.

Endereço: Rua Ceres, 1157, Edson Queiroz, CEP 60834-180, Fortaleza, CE, Brasil.

E-mail: janeeyreœunifor.br

\section{Augediva Maria Jucá Pordeus}

Enfermeira. Doutora em Enfermagem. Professora Assistente VI do Centro de Ciências da Saúde da Universidade de Fortaleza. Técnica do Núcleo de Epidemiologia da Secretaria de Saúde do Ceará. Endereço: Rua Francisco Virgílio Vasconcelos, 68 Ap. 30I, Meireles, CEP 60165-060, Fortaleza, CE, Brasil.

E-mail: augedivaœsaude.ce.gov.br

\section{Renata Carneiro Ferreira}

Enfermeira. Mestranda em Saúde Coletiva. Centro de Ciências da Saúde. Universidade de Fortaleza.

Endereço: Rua Doutor Manoel Teófilo, 128, Parangaba, CEP 60710290, Fortaleza, CE, Brasil.

E-mail: renatadaळibest.com.br

\section{Deborah Pedrosa Moreira}

Enfermeira. Mestranda em Saúde Coletiva. Centro de Ciências da Saúde. Universidade de Fortaleza.

Endereço: Rua Barão de Aracati, 1502, Ap. 703, Aldeota, CEP 6011508I, Fortaleza, CE, Brasil.

E-mail: deborahpm®terra.com.br

\section{Potívea Bezerra Maia}

Enfermeira da Estratégia Saúde da Família. Jaguaruana, Ceará.

Endereço: Rua Leonardo Mota, 1855, Ap. 1600, Aldeota, CEP 60160041, Fortaleza, CE, Brasil.

E-mail: potivea®edu.unifor.br

\section{Kátia Costa Saviolli}

Aluna do curso de Terapia Ocupacional do Centro de Ciências da Saúde da Universidade de Fortaleza. Ex-Bolsista de Iniciação Científica da FUNCAP.

Endereço: Rua Frei Vicente Salvador, 982, Montese, CEP 60410-400, Fortaleza, CE, Brasil.

E-mail: katiasavioliøhotmail.com

0 presente trabalho foi realizado com o apoio do Ministério da

Saúde/DECIT e SESA/Ceará.

\section{Resumo}

Este trabalho descreve os fatores de risco para violência doméstica e coletiva contra a mulher, a compreensão dessas mulheres sobre a violência doméstica e coletiva e a aplicação do Modelo Calgary de Avaliação em Famílias (MCAF), em moradores de uma comunidade, em Fortaleza, Ceará. Foi um estudo de caso com 20 famílias, e, entre estas, foram escolhidas quatro que apresentaram maior potencial para violência contra a mulher, em 2005. Os resultados mostraram que as mulheres conhecem alguns fatores de risco para violência, porém aparentam não saber agir no sentido de evitá-la; as condições desfavoráveis de habitação e entorno familiar são percebidos como risco. A violência é percebida, principalmente pela mulher, como "algo comum" no cotidiano do casal. O álcool, o uso da droga ilícita, o desemprego e a baixa escolaridade também agravam a ocorrência da violência entre as famílias participantes. Conclui-se que as mulheres enfrentam, em seu cotidiano, diferentes modos de violência. Elas vivem em um sistema de isolamento social e político que pode contribuir para a reprodução de mecanismos mais complexos de violência, impedindo-as de manifestarem-se de forma mais autônoma.

Palavras-chave: Famílias; Prevenção; Violência contra a mulher; Modelo Calgary. 


\section{Abstract}

This article describes risk factors for domestic and collective violence against women, these women's understanding of domestic and collective violence and the administration of the Calgary Family Assessment Model (CFAM) to community residents in the city of Fortaleza, state of Ceará. It was a case study conducted in 2005 with 20 families. Four families were selected because they showed high potential for violence against women. The results showed that the women know about some risk factors for violence; however, they apparently do not know how to act with the objective of avoiding it. Unfavorable housing and family conditions are perceived as risk factors. Violence is perceived by the woman as something common in the daily life of the couple. Alcohol, illicit drugs, unemployment and low schooling constitute aggravating factors in the occurrence of violence among the participant families. It is concluded that the women face, in their daily lives, different modes of violence. They live in a social and political isolation system that may contribute to the reproduction of more complex mechanisms of violence, preventing them from expressing themselves with autonomy.

Keywords: Families; Prevention; Violence Against Women; Calgary Model.

\section{Introdução}

A violência é um fenômeno de causalidade complexa, por vezes controverso e de mensuração problemática, porque o reconhecimento de sua ocorrência envolve análises de valores e práticas culturais, como também em seus componentes causais sócio-históricos, econômicos e subjetivos (Minayo, 2005).

A Organização Mundial de Saúde (OMS) define violência como o uso intencional da força física ou do poder, real ou ameaça, contra si próprio ou contra outra pessoa, grupo ou comunidade, que resulte ou possibilite resultar em lesão, morte, dano psicológico, deficiência de desenvolvimento ou privação (Krug e col., 2002; Dahlberg e Krug, 2006).

A Assembléia Mundial de Saúde (WHA), em sua Resolução 49.25 de 1996, declarou a violência como um dos problemas de saúde pública, e solicitou à OMS que desenvolvesse uma tipologia da violência, bem como os vínculos entre elas. Assim, essa tipologia foi especificada em três categorias: violência autoinfligida; violência interpessoal e violência coletiva (Krug e col., 2002; Dahlberg e Krug, 2006).

Violência auto-infligida é aquela em que a pessoa provoca a si mesma e envolve o comportamento suicida e as autolesões. A interpessoal compreende a violência da família e do parceiro, que ocorre entre membros da família e parceiros íntimos, mas não exclusivamente dentro de casa; a violência comunitária se manifesta entre pessoas sem laços de parentesco, que podem se conhecer ou não, geralmente fora de casa. A violência coletiva é subdividida em violência social, política e econômica (Krug e col., 2002; Dahlberg e Krug, 2006).

A literatura emprega também a terminologia violência doméstica fazendo alusão à violência da família e do parceiro (Oliveira, 2007; Schraiber e col., 2005). Desse modo, a OMS (2005) reforça que a violência doméstica é aquela praticada por parceiro íntimo, e definida como qualquer tipo de violência que a mulher sofre nas mãos de parceiro íntimo ou ex-parceiro. Configura-se como o tipo mais comum e universal de formas de violência experimentadas por mulheres. Com base nas definições sobre a tipologia da violência preconizada pela OMS (2005), o estudo adota os conceitos de violência doméstica e coletiva.

A família nos últimos anos vem passando por um processo de fragmentação. Isso se deve a mudanças 
sociais, políticas e econômicas, perpassando o processo da violência que ocorre no meio doméstico (Martins e col., 2007). Biasoli-Alves (1999) descreve vários fatores que exercem influência no bem-estar da família, o isolamento desta, a diminuição do prestígio da mulher donade casa e a diminuição do valor social na função de criar os filhos, pois, atualmente, a mulher tem seus filhos em um curto espaço de tempo.

A grande mobilidade nos empregos leva todos os membros da família à necessidade de um processo constante de adaptação acrescido da distância com as famílias de origem e, conseqüentemente, da quebra da rede de apoio. Além dessas mudanças, houve o impacto da televisão, da pobreza, da mudança de valores e papéis. Tudo isso tem afetado a vida das pessoas no círculo familiar, trazendo o aumento dos conflitos e originando as rupturas emocionais e físicas.

A violência no ambiente doméstico ocorre com frequêencia e é difícil de ser reconhecida, pois é cercada pelo medo, dor e silêncio das mulheres (Brasil, 2006a). Ela varia desde humilhações, ameaças, acusações até a violência física. Gomes e colaboradores (2005) ressaltam que todas essas expressões são toleradas, silenciadas, desculpadas pela dependência das mulheres em relação aos homens ou explicações do tipo: os homens não controlam seus instintos, estupradores são doentes mentais, as mulheres gostam de homens rudes.

Diante da complexidade do fenômeno é imprescindível a realização de estudos que ampliem a visibilidade do tema e da diversidade das situações de violência contra as mulheres. É preciso romper com esse continuísmo que repercute, de modo significativo, nas esferas política, econômica, social e cultural do país, contribuindo com a qualidade de vida das mulheres e das pessoas com quem se relacionam.

Nesse sentido, visando contribuir com as discussões sobre as violências contra a mulher, o estudo: (i) retrata o perfil sociodemográfico de famílias moradoras na Comunidade do Dendê, em Fortaleza, Ceará; (ii) identifica a relação com os fatores de risco para violência doméstica e coletiva contra a mulher; (iii) investiga a compreensão dessas mulheres sobre fatores de risco para as situações de violência doméstica e (iv) aplica o Modelo Calgary de Avaliação e Intervenção da Família (MCAIF). Neste artigo optou-se pelo recorte referente à avaliação das famílias.

\section{Metodologia}

Este artigo é um recorte de uma pesquisa que envolveu a avaliação dos acidentes domésticos contra crianças e violência contra a mulher das famílias pesquisadas na comunidade do Dendê (Maia ${ }^{1}$ ). Os dados aqui demonstrados referem-se apenas à violência doméstica e coletiva contra a mulher.

Configura-se como um estudo de caso na identificação de fatores de risco para situações de violência contra a mulher, no contexto doméstico e coletivo, de famílias residentes na Comunidade do Dendê, Fortaleza, Ceará. Para se aproximar das concepções das famílias do estudo sobre o reconhecimento desses fatores, utilizou-se o Modelo de Calgary de Avaliação e Intervenção da Família como instrumento de coleta dos dados (Wright e Leahey, 2002).

Leopardi e colaboradores (2002) defendem que se pode aplicar o estudo de caso para evidenciar condições de vida, meios de sobrevivência, formas de comportamento sobre determinado fenômeno. Este pode ser utilizado com um sujeito, uma instituição - família, escola, hospital - procurando observar tudo que seja possível.

Situando o espaço geográfico, a Comunidade do Dendê é uma área de vulnerabilidade social, econômica e cultural, com aproximadamente 10.ooo habitantes (Sales e Leite, 2005). Pesquisas realizadas nessa comunidade mostraram que ao longo dos anos ela tem passado por mudanças demográficas e estruturais, apontando um território heterogêneo. 0 número de habitantes cresce rapidamente, percebendo-se diferenças socioeconômicas e culturais marcantes (Diniz e Fraga, 2005; Landim e col., 2004).

Integraram esta pesquisa 20 famílias residentes na Comunidade, selecionadas aleatoriamente na intenção de se obter um diagnóstico situacional sobre violências contra a mulher, sendo o informante-chave a própria mulher (dona de casa).

A coleta de dados realizou-se mediante visitas domiciliares, semanais, no período de julho a setembro

1 MAIA, P. B. Fatores de risco para situações de acidentes e violência no ambiente familiar. 2005. Trabalho de Conclusão de Curso (Graduação em Enfermagem) - Universidade de Fortaleza, Fortaleza, 2005. 
de 2005. Para tal, utilizou-se um instrumento estruturado com variáveis socioeconômicas e culturais (idade, estado civil, escolaridade, naturalidade, religião, renda, situação empregatícia, número de membros familiares, tipo de família, chefe familiar) e referentes aos possíveis fatores de risco relacionados à violência contra a mulher (consumo de drogas lícitas e ilícitas, presença de armas e de violência doméstica). Além desse instrumento, procedeu-se à observação focalizada e, posteriormente, à participante. Para análise foram realizadas leituras flutuantes e exaustivas de todo o material para buscar, de modo intencional, famílias que evidenciaram fatores de risco às situações de violências contra a mulher, para a aplicação do Modelo Calgary de Avaliação da Família - MCAF (Wright e Leahey, 2002).

Essas situações relacionaram-se à presença de fatores de riscos relatados pela literatura, que salienta o álcool e o uso de drogas ilícitas, o desemprego, a falta de afeto e de diálogo, dentre outros, como desencadeantes das violências contra a mulher (Bonifaz e Nakato, 2004; Sabroza e col., 2004; Roque e Ferriani, 2002; Souza ${ }^{2}$ ). Atendendo a esse critério de intencionalidade foram identificadas quatro famílias.

Este modelo é uma estrutura multidimensional, integrada, baseada em sistemas, cibernética, de comunicação e fundamentos teóricos de mudança. É composto por três categorias principais de configuração familiar: estrutural, desenvolvimento e funcional (Wright e Leahey, 2002).

Este artigo restringiu-se à avaliação da categoria estrutural, que descreve as características familiares, e abrange três subcategorias: (i) interna - relaciona o contexto familiar sob a composição dos membros, gênero, orientação sexual, ordem de nascimento, subsistemas e limites da família; (ii) externa - abrange a família em sua forma extensiva e sistemas mais amplos no qual a família interage; e (iii) contexto - a conjuntura, a etnia, a raça, a classe social, a religião e a espiritualidade da família (Wright e Leahey, 2002).

Além da descrição das famílias, procedeu-se a construção do genograma, para delinear as estruturas internas e externas. 0 genograma é um diagrama de todo o grupo familiar, representado por uma árvore genealógica da estrutura interna da família. É utilizado para desencadear informações úteis a respeito do desenvolvimento e outras áreas de funcionamento desta. É de grande importância desenhar um círculo ao redor dos atuais membros da família para fazer a distinção entre os vários familiares (Wright e Leahey, 2002).

O estudo obedeceu aos preceitos éticos, de acordo com a Resolução 196/1996, atendendo aos seguintes princípios: autonomia, beneficência, não-maleficência, justiça e eqüidade (Brasil, 1996) e foi aprovado pelo Comitê de Ética em Pesquisa da Universidade de Fortaleza (parecer $n^{0}$. 307/2004).

\section{Resultados e Discussão}

A idade preponderante das mulheres situava-se entre 23 e 60 anos. Das 20 mulheres, duas são viúvas, duas separadas e 16 vivem maritalmente. Dentre essas, cinco estão na segunda união, caracterizando o tipo de família reconstituída. Nesse sentido, Gomes e Pereira (2005) destacam que mudanças no âmbito socioeconômico e cultural, decorrentes da globalização, vêm interferindo na dinâmica e estrutura familiar, possibilitando alterações em seu padrão tradicional de organização. Dessa forma, o aumento das famílias recompostas, decorrentes do número crescente de separações e divórcios, aumenta também o número de pessoas que vivem sozinhas.

Meneghel e colaboradores (2003), em seu estudo, identificaram que as mulheres buscam formas de resistir à violência no seu cotidiano, a exemplo da separação e reconstituição da família, mesmo que, em muitas situações, o ciclo de violência retorne com o novo companheiro. Gomes e Pereira (2005) retratam que, para a família pobre, marcada pela fome e miséria, esta caracterizada por baixos salários e condições insalubres de sobrevivência, a casa representa um espaço de privação, de instabilidade e de separação dos laços afetivos e de solidariedade. A família tem como característica laços fortes de sentimentos, característica que é abalada pela situação social em que se encontra.

\footnotetext{
2 SOUZA, E. R. (Org.). Módulo 4 - É possível prevenir a violência? Refletindo sobre risco, proteção, prevenção e promoção da saúde. In: SOUZA, E. R. (org.). Curso impactos da violência na saúde. Unidade I - Bases conceituais e históricas da violência e setor saúde. Rio de Janeiro: EAD/ENSP, 2007. p. 80-111.
} 
Quanto aos companheiros, a idade variou entre 24 e 41 anos. Em cinco famílias as mulheres eram mais velhas do que o companheiro, com até oito anos de diferença. Em relação à escolaridade das mulheres, seis eram analfabetas; uma alfabetizada; onze tinham o ensino fundamental incompleto e duas referiram não ter completado o ensino médio. Das 20 famílias, 13 tinham pelo menos uma pessoa natural do interior do Estado, evidenciando o êxodo rural.

Diniz e Fraga (2005), ao traçarem o perfil social e demográfico da Baixada do Aratu, uma microárea da Comunidade do Dendê, identificaram que o alto índice de desemprego ou subemprego está relacionado com a baixa escolaridade e, nesse caso, "aborta" perspectivas de melhoria de vida dos moradores, perpetuando a situação de pobreza extrema. O Brasil apresenta insuficiência e desigualdade na distribuição da taxa de analfabetismo, havendo disparidade em relação ao espaço geográfico, refletindo a história social, econômica e cultural de cada região (Brasil, 20o6b). A comunidade do Dendê reflete essa carência educacional, evidenciando traços da exclusão social.

A renda familiar de 16 famílias era menor ou igual a um salário mínimo, enquanto quatro famílias recebiam até dois salários. Em dez famílias todos os membros estavam desempregados, vivendo de ajuda de amigos e familiares, ou fazendo "biscate". Em sete famílias, pelo menos um membro trabalhava; duas famílias eram pensionistas (INSS) e uma estava recebendo o seguro desemprego.

Pesquisa realizada com mulheres vítimas de violência doméstica, atendidas em hospitais de emergência nas zonas Norte e Sul do Rio de Janeiro, identificou uma predominância da renda familiar entre um a três salários mínimos (Deslandes e col., 200o). Esses dados não condizem com a realidade das mulheres participantes deste estudo.

O número de pessoas vivendo em cada residência variou entre duas e dez. Destaca-se, portanto, o aglomerado nessas famílias, pois as casas possuem no máximo três cômodos, incluindo o banheiro. Nesse sentido, discorrendo sobre bem-estar familiar e sua relação com o ambiente, Biasoli-Alves (1999) relata que o espaço diminuído, tanto na casa como no apartamento, influencia no bem-estar da família.

Quanto ao tipo de família, 13 são nucleares, quatro monoparentais e três ampliadas. Esses dados ratifi- cam o que Mioto (1999) destacou sobre o predomínio das famílias nucleares, porém com tendência ao aumento das famílias monoparentais e do número de mulheres como chefes. Considerando a espiritualidade, o catolicismo foi referido por 13 famílias, sete delas declararam-se adeptas das concepções evangélicas. A maioria delas, porém, destacou não ser praticante, pois a igreja ficava distante de suas moradias.

Em relação ao comportamento de risco entre os membros da família, em 11 delas pelo menos um ou mais membros afirmaram consumir álcool de maneira abusiva, fator que tem gerado discussão entre os casais. O uso da droga ilícita, especificamente a maconha, foi salientado por três famílias. Nas 20 famílias visitadas não foi presenciado armas branca (punhal, peixeira, estiletes, canivetes etc.) ou de fogo, exceto os utensílios domésticos a exemplo das facas de cozinha. Estudiosos argumentam que o uso de drogas, tanto lícitas como ilícitas, na maioria das vezes, está presente no contexto da violência doméstica contra a mulher (Marinheiro e col., 20o6).

A comunicação não-verbal evidenciou jargões e abordagens que se mesclaram com a violência. No entanto, algumas mulheres negaram, inicialmente, que houvesse violência entre os pares. Nessa ótica, identificou-se que, no senso comum, a percepção da violência ainda é distorcida, sendo declarada como tal apenas a agressão física. Por outro lado, a vergonha e o medo de falar abertamente, porque co-habitam com esta violência, pode induzir as mulheres a silenciar sobre a violência sofrida e praticada.

De acordo com Peçanha (1999), as famílias tendem a ocultar a agressividade e a negar seus conflitos a fim de preservar o mito da coesão e harmonia familiar. Neste estudo, três mulheres sentiam-se intimidadas, 11 disseram que sofriam agressão verbal e seis afirmaram que "achavam normal" a ocorrência de "discussão no casamento".

A agressão física foi relatada por cinco mulheres e duas destas se separaram do companheiro, pois não agüentaram a situação; três sofreram agressão alguns dias antes da pesquisa. Das que foram agredidas, duas relataram que essas agressões existem desde o início do relacionamento, achavam até natural e disseram que também batiam em seus maridos. Uma destas referiu que a agressão ocorria quando o marido chegava alcoolizado, e que em uma dessas vezes ele já tentou 
sufocá-la, fato que foi comunicado à polícia, resultando na prisão de seu marido por uma noite. Depois do ocorrido, essa mulher relatou que o casal convive sob "o mesmo teto, mas não se fala".

Estudo entre dois grupos de mulheres, realizado na cidade do Rio Grande do Sul, evidenciou em um deles que a violência por parte dos homens esteve presente na história de vida de todas as mulheres. 0 comportamento violento do companheiro foi relatado nas situações de litígio entre os casais, nas atitudes de homens que abandonam o lar e levam os móveis, arrombam a casa e ameaçam de morte suas mulheres (Meneghel e col., 2003).

\section{Modelo Calgary da Avaliação da Família}

\section{Descrição das famílias e as violências contra a mulher}

\section{Família 1 (F1)}

É uma família composta pela mãe Esperança (28 anos), ensino fundamental incompleto, católica; o pai (29 anos), ensino fundamental completo; e quatro filhas, com seis, três, um ano e 11 meses e a mais nova com seis dias. Apenas uma se encontrava na escola, cursando a educação infantil (Jardim II).

A família morando em uma casa feita de tijolos, coberta com telhas, constituída de três cômodos: sala, cozinha e banheiro. 0 marido desempregado estava recebendo seguro desemprego (um salário mínimo). Ingeria bebida alcoólica e fumava maconha, fato que tinha causado muito briga, porém nenhuma agressão física. Esperança relatava que, quando o marido estava bêbado, ela evitava conversar e, muitas vezes, ia para a casa de seus pais, que residem na mesma Comunidade. Seu pai com 69 anos, aposentado; a mãe, 55 anos, doméstica. Quando passa por algum problema, Esperança pede ajuda a sua irmã. Sobre a vizinhança, deu nota sete para a vizinha da direita e oito para a da esquerda. Refere buscar a unidade básica de saúde mais próxima quando necessita de serviço médico. Nega possuir armas de fogo em sua casa, porém tem uma faca de cozinha (na verdade, um punhal) que é guardada dentro do forno do fogão.

\section{Genograma da Família I}

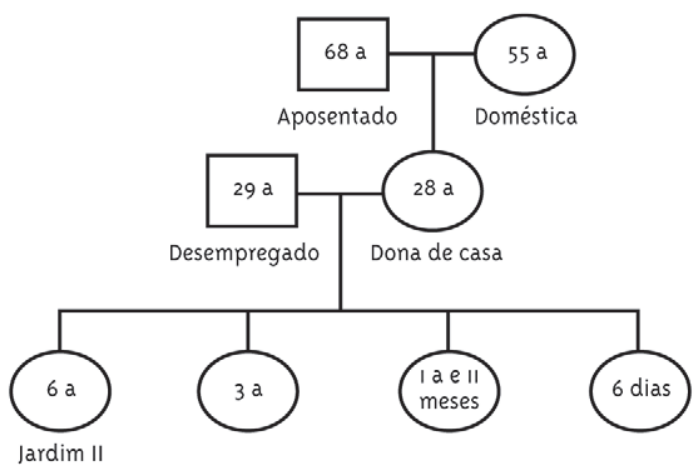

\section{Família 2 (F2)}

Trata-se de uma família nuclear composta pela mãe (Paciência) de 29 anos, dona de casa, evangélica e seu marido (30 anos, desempregado). Disseram ter cursado o ensino fundamental incompleto. A filha mais velha (10 anos) cursa a $3^{\text {a }}$ série do ensino fundamental e a mais nova tem seis meses. Residiam há seis meses em uma casa com dois cômodos e utilizavam o banheiro da casa da mãe de Paciência, que mora atrás de sua casa. Paciência tem mais contato com a sua mãe, seu pai já faleceu. Quando ela necessitava de ajuda procurava a mãe e a irmã. Informou que quando precisava dos serviços de saúde buscava a unidade básica mais próxima de sua casa. Quanto à vizinhança, deu nota nove para a da direita, sua cunhada; cinco para a da esquerda, porque esta era "fofoqueira". Sobre ter sofrido violência física, inicialmente negou, mas com o decorrer da entrevista, disse que o marido tentou sufocá-la na última vez que bebeu. Depois disso, referiu que tem medo de que algo pior aconteça e que estava decidida a pedir o divórcio.

\section{Genograma da Família 2}

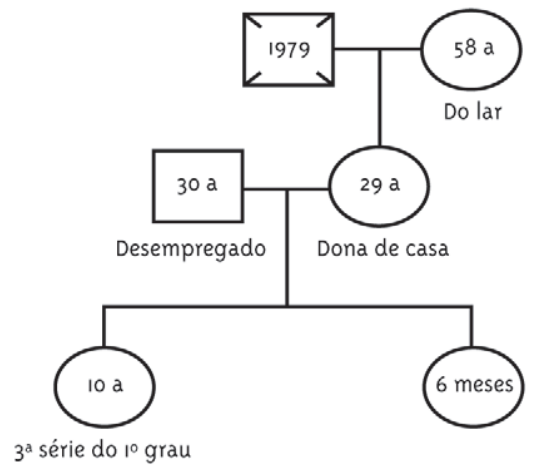




\section{Família $3\left(F_{3}\right)$}

É uma família ampliada composta pelo pai, 41 anos, desempregado, ensino fundamental incompleto. A mãe Dona D, 48 anos, analfabeta, evangélica, três filhos, reside com uma nora e quatro netos. Dona D referiu que teve onze abortos espontâneos, só depois nasceram os seus três filhos. 0 mais velho, com 22 anos, não trabalha e estudou até o ensino fundamental completo. Este convive consensualmente com uma moça, de 20 anos, e mais três filhos, sendo um casal de gêmeos (quatro anos) que estudam o Jardim II, e o filho mais novo que tem um ano e três meses. A filha do meio da Dona D estava com 18 anos, grávida; e era mãe de um garoto com dois anos e quatro meses. A mais nova, 16 anos, abandonou os estudos. A família vivia de ajuda de amigos e familiares. Dona D estava casada há 22 anos com seu atual marido. Manteve um relaciona- mento anterior, vindo a separar-se devido a constantes ameaças e agressão verbal. Relatou que o pai faleceu, que sua mãe morava no interior do Ceará, e não tinha contato com sua família. Quando precisa de ajuda pede às pessoas da comunidade. Nos últimos cinco anos mudou de casa uma vez, e deu nota seis para a vizinhança. Dona D relatou que o marido, a filha gestante, um dos netos e ela estão fazendo tratamento para tuberculose. Referiu ainda que o tratamento é muito difícil, pois não se alimentam todos os dias. Disse também que a família tem sofrido com o preconceito da comunidade e de familiares de seu marido, pois deixaram de freqüentar sua residência por causa da doença. 0 marido sente-se culpado e acha que transmitiu a doença para a família. Diante de tal desespero, explicou que ele ingere bebida alcoólica para esquecer os problemas.

\section{Genograma da Família 3}

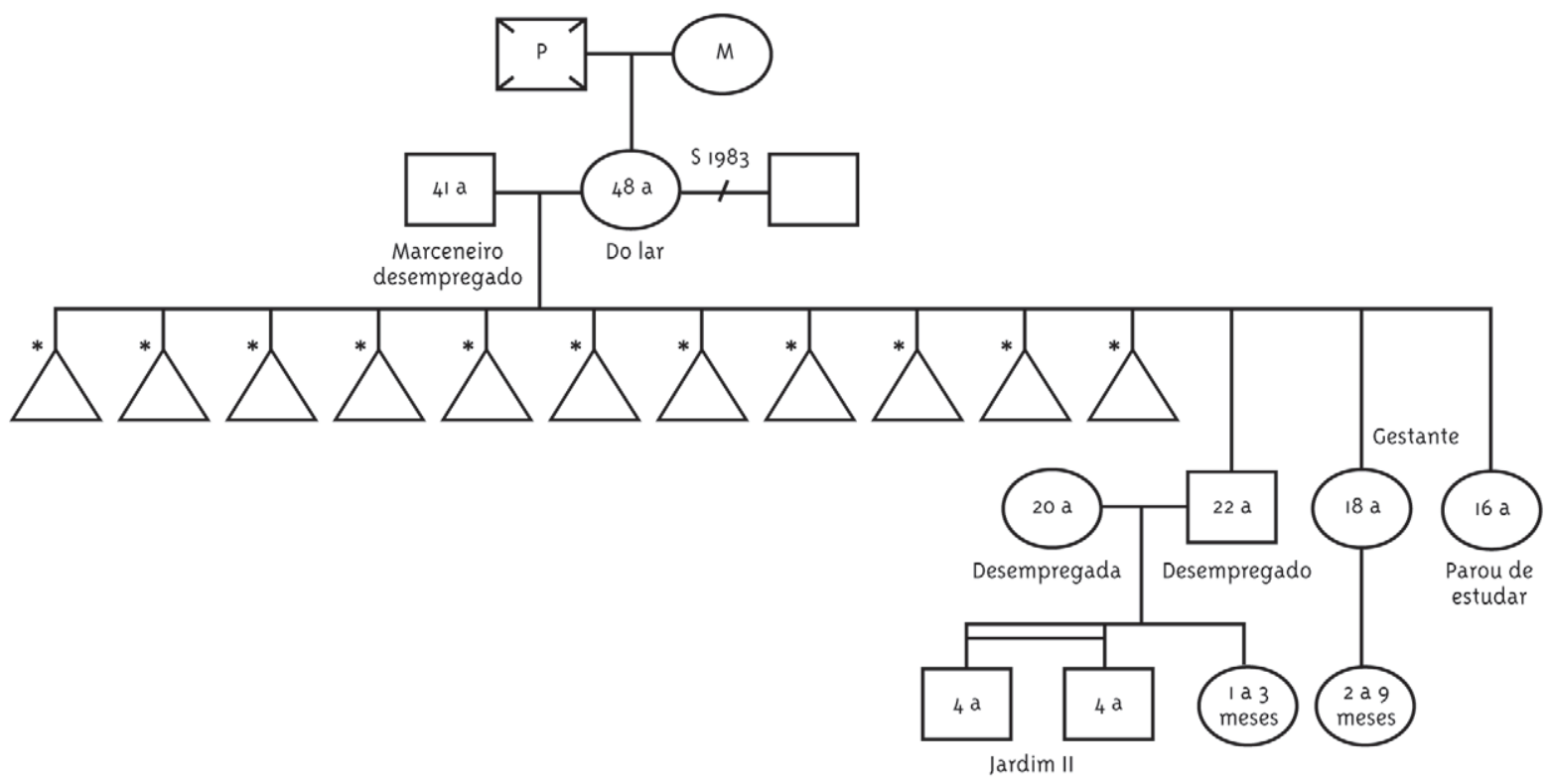

\section{Família 4 (F4)}

Perseverança, 50 anos, católica, ensino fundamental incompleto, viúva há 14 anos, três filhos de seu primeiro matrimônio. 0 mais velho com 27 anos, casado, trabalhando com entregas, morando com a esposa. A outra filha, com 25 anos, casada, dona de casa, mora nas proximidades de sua mãe; e o terceiro, 20 anos, também trabalhando fazendo entregas. Perseverança, na segunda união, teve um aborto e uma filha. Esta, a caçula da família, na época com 10 anos, estava na $4^{\mathrm{a}}$. série, sendo a única filha que com ela morava. Perseverança "largou" seu segundo relacionamento, pois sofria constantemente agressão física e verbal, conforme referiu. Perseverança é adotada e informou que sua mãe adotiva faleceu há 23 anos, e não teve contato com o pai adotivo. Quando surgem problemas conversa com a filha; nos últimos cinco anos mudou uma vez de casa. Referiu procurar a unidade básica de saúde mais próxima para a resolução de seus problemas de saúde, e deu nota 10 para a vizinhança. 


\section{Genograma da Família 4}

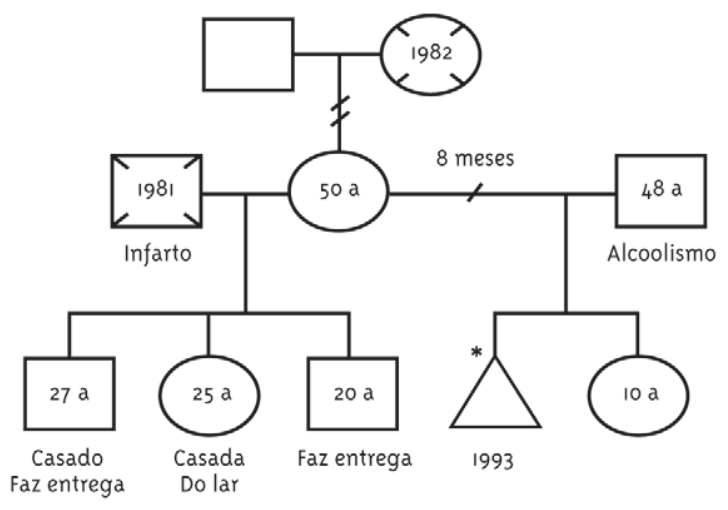

\section{Avaliação Estrutural das Famílias}

Segundo Wright e Leahey (2002), é necessário que, ao avaliar uma família, seja examinada sua estrutura, ou seja, quem faz parte dela, qual é o vínculo afetivo entre seus membros em comparação com os outros indivíduos e qual é o seu contexto. A estrutura familiar compreende três aspectos: estrutura interna, estrutura externa e contexto.

É nessa esfera que está inserido o estudo sobre o MCAF, possibilitando, assim, o entendimento de que a família é o principal grupo social atuante na formação do indivíduo, tendo como papel fundamental o atendimento às necessidades biopsíquica, socioespiritual e cultural de cada um de seus componentes (Ximenes e col., 2004).

\section{Estrutura Interna}

A estrutura interna abrange seis subcategorias: composição da família, gênero, orientação sexual, ordem de nascimento, subsistemas e limites. Atualmente, de acordo com Wright e Leahey (2002), há diversas formas de composição familiar, como a família de procriação biológica, a família nuclear, de um só genitor, adotiva, comum e de casal homossexual.

Mioto (1999), corroborando com as autoras, afirma não ser possível falar de família, ou simplesmente um modelo de família. Admitem-se cada vez mais diversificações de formas de famílias ou de amigos familiares que não mais o tradicional pai, mãe e filho.

A família é constituída por indivíduos com fortes vínculos emocionais, com sentido de posse, inclina- ção a participar da vida uns dos outros. Para Wright e Leahey (2002), a definição adotada para família é aquela que seus membros dizem. As autoras relatam ainda que a composição das famílias tem sofrido alterações temporárias ou permanentes.

No estudo foram encontradas famílias nucleares, monoparentais e ampliadas. Em uma família, a composição havia sido alterada há pouco tempo, pois houve o nascimento de um bebê. A família estava se adaptando à chegada de um novo membro.

Sobre a influência do gênero na família, Wright e Leahey (2002) dizem que depende do modo como as famílias transmitem para seus membros os papéis do homem e da mulher na sociedade. 0 sexo é um conjunto de crenças sobre as expectativas da conduta e experiências femininas e masculinas. Essas crenças foram desenvolvidas por influências culturais, religiosas e familiares, bem como pela orientação sexual e de classe.

A violência de gênero tem acontecido ao longo da história. No Brasil, o Código Criminal de 1830 atenuava o homicídio praticado pelo marido quando a mulher praticava adultério. Porém, se o marido mantivesse relação constante com outra mulher, essa situação constituía concubinato e não adultério (Blay, 2003). Corroborando essa premissa, a Organização das Nações Unidas - ONU (2003) afirma que a violência doméstica tem origem em todo um contexto social. A agressão a mulheres reflete as amplas estruturas de desigualdade econômica e social na sociedade.

Nas quatro famílias entrevistadas, três mulheres já haviam sofrido agressão física por parte dos companheiros. Nesse sentido, apesar de a violência de gênero não ser foco do estudo, o MCAF salienta a importância dessa subcategoria para a compreensão da estrutura familiar. Assim sendo, não se pode omitir, neste estudo, sua ocorrência a exemplo da F4, pois existe exposição crônica e repetição das histórias de violências pelas gerações de mulheres.

Quanto à ordem de nascimento, Wright e Leahey (2002) afirmam que esta subcategoria refere-se à posição do nascimento na família, a relação com a idade e o sexo. As autoras ressaltam que a diferença de idade entre os irmãos constitui fator relevante na avaliação das famílias, e pode influenciar, futuramente, na organização da personalidade do indivíduo. Porém, na medida em que este se relaciona com o ambiente externo, a família também sofre influências. 
Os subsistemas constituem uma categoria traçada por geração, sexo, idade, interesse, função ou história. Cada pessoa na família pertence a vários subsistemas diferentes, desempenhando poder e habilidades diversas (Wright e Leahey, 2002). Esse acontecimento esteve presente em todas as famílias, porém na família ampliada cada indivíduo ocupa um número maior de subsistemas e requer, por parte deste, maior habilidade para adaptar-se às necessidades de cada subsistema. Das quatro famílias avaliadas, era evidente a acentuada presença dos subsistemas na família ampliada (F3).

Os limites referem-se aos sistemas e subsistemas e têm como função proteger a diferenciação destes entre si. Os limites podem ser difusos, rígidos ou permeáveis. 0 limite difuso ocorre quando um membro adquire o papel ou a função de um adulto; o rígido, por sua vez, ocorre quando são impostas condições rigorosas dentro desse sistema e no limite permeável há uma flexibilidade adequada dentro da família (Wright e Leahey, 2002). Nas famílias, esses limites difusos e rígidos também favorecem a violência contra a mulher.

\section{Estrutura Externa}

Este aspecto inclui duas subcategorias: família extensa e sistemas mais amplos. A família extensa inclui a família de origem e a família de procriação, assim como a atual geração e membros da família adotiva. Os vínculos de lealdade presentes nestas famílias podem ser invisíveis, porém são forças influentes na estrutura familiar. Esses vínculos ocorrem mesmo quando as famílias estão separadas por grandes distâncias demográficas (Wright e Leahey, 2002).

Neste estudo, estas subcategorias foram enfocadas quando as famílias discorreram onde moravam seus pais, qual parente era considerado mais próximo, a quem pedia ajuda quando surgiam problemas na família e com qual membro da família não mantinha contato. Os resultados encontrados divergiram quanto aos vínculos familiares. As F1 e F2 recebiam total apoio de sua família extensa e possuíam grande vínculo afetivo, enquanto a F3 não tinha contato com ninguém e a F4 se relacionava apenas com os filhos. Ao evidenciar com quais familiares elas tinham menos contato, surgiram as seguintes respostas: a F1 era com as tias maternas que moravam no interior; a F3 reafirmou seu isolamento familiar e a $\mathrm{F}_{4}$ disse que não contatava o pai adotivo.
Sobre a quem estas famílias procuravam quando necessitavam de ajuda, na família 1 o relacionamento fraterno sobrepôs o paternal; na família 2 conversava com a mãe e a irmã; na família 3 buscava ajuda das pessoas da comunidade e, na família 4, nos filhos. Quanto aos sistemas mais amplos, referem-se aos sistemas sociais, como as instituições e pessoas com quem as famílias têm contato significativo (Wright e Leahey, 2002).

A Política Nacional de Redução da Morbimortalidade por Acidente e Violência ressalta os fundamentos de promoção da saúde relativos ao fortalecimento da capacidade dos indivíduos, das comunidades e da sociedade em geral para desenvolver, melhorar e manter, saudáveis, condições e estilos de vida. Esse fortalecimento inclui a criação de ambientes, a reorganização dos serviços de saúde, o reforço da ação comunitária e o desenvolvimento de aptidões pessoais (Brasil, 2005).

Atualmente, diversas organizações desenvolvem guias para nortear as ações de profissionais de saúde, de modo que se possa identificar, apoiar e dar o devido encaminhamento às vítimas, pois os serviços de saúde são portas de entrada das mulheres em situação de violência. Tais medidas resultam da compreensão de que a violência representa uma violação dos direitos humanos, consistindo, ainda, em importante causa de sofrimento e risco para diversos problemas de saúde de cunho físico e psicológico (Silva, 2003).

\section{Contexto}

Para Wright e Leahey (2002), o contexto é o conjunto de informações relevantes a algum fato ou personalidade. Cada sistema familiar está interligado com sistemas mais amplos que vizinhança, classe, religião e pais, e recebe influências deles. 0 contexto possui cinco categorias: etnia; raça; classe social; religião e espiritualidade; e ambiente. Quanto à etnia, segundo Wright e Leahey (2002), esta subcategoria refere-se ao conceito de unidade da família derivado da combinação histórica, raça, classe social e religião. Descreve a qualidade de processos sutis e manifestos transmitidos por gerações pela família, sendo reforçados pela comunidade adjacente.

As famílias dos imigrantes poderão sofrer impacto cultural temporário, dificuldade econômica, racismo, mudanças na família extensa e sistema de apoio. No presente estudo foi escolhido inicialmente cinco famí- 
lias que apresentaram maior fator de risco para acidentes e violência. Uma das famílias, durante a avaliação diagnóstica, relatou que morava no interior do Ceará e que havia se mudado para Fortaleza há três meses. Ainda informou que a família estava com dificuldades financeiras, pois não havia encontrado emprego e, além disso, não tinha nenhum familiar na cidade.

Um dos filhos do casal, com neuropatia, necessitava de cuidados especiais e a família não sabia a quem recorrer. $\mathrm{O}$ fato de a família ser descendente de índios, morar anteriormente no sertão cearense e vir a morar em uma favela foi motivo de conflitos na família, evidenciados pelas freqüentes discussões entre o casal. Ao retornar para aplicar o MCAF, os vizinhos informaram que a família havia retornado para o interior do estado.

Quanto à raça, esta influencia na identificação essencial do indivíduo e do grupo. Wright e Leahey (2002) ressaltam que atitudes estereotipadas e discriminatórias por parte do profissional da saúde podem influenciar e comprometer a sua interação e o seu relacionamento com a família. Ressaltam que a classe social molda os resultados educacionais, de renda e ocupacionais. Informam que cada classe social tem seus valores, estilo de vida e comportamentos que influenciarão cuidados de saúde. A avaliação de classe social possibilita ao profissional de saúde entender os fatores de estresse pelos que a família enfrenta, mediante os recursos disponíveis.

Entre as quatro famílias, em duas os pais estavam desempregados (F2 e F3); em outra (F4), a dona de casa recebia pensão do INSS; na família 1, o marido recebia o seguro desemprego. Ressalta-se a relação entre o grau de escolaridade e o emprego. Nas famílias entrevistadas, a maioria dos membros possuía o ensino fundamental incompleto. Esses dados reforçam a premissa de que nenhum estado brasileiro se enquadra nos níveis ideais de instrução internacionalmente aceitáveis, estando mais próximos destes o Distrito Federal e alguns estados das regiões Sul e Sudeste (Brasil, 2006a).

Quanto à religião, para Wright e Leahey (2002) influenciam os valores, o tamanho, os cuidados de saúde e os hábitos sociais da família. A religião pode influenciar as crenças e a maneira como a família enfrenta a doença. Observando as famílias entrevistadas, foi constatado que duas são católicas (F1 e F4) e as outras duas evangélicas ( $\mathrm{F}_{2}$ e F3). Na família 3 foi observado o conformismo e a desculpa de que estavam naquela situação financeira difícil porque Deus queria. Estudos apontam uma forte relação entre ter religião e exercê-la, com a melhoria das condições de saúde. Esta também é considerada um fator protetor para consumo de drogas em diversos níveis (Sanchez e Nappo, 2007), considerando que a droga se coloca como fator de risco para a violência.

Em relação ao ambiente, esta subcategoria abrange aspectos da comunidade mais ampla, vizinhança e lar. De acordo com Wright e Leahey (2002), os fatores ambientais, tais como adequação de espaço, privacidade e acesso a escolas, creche, recreação e transporte público, influenciam o funcionamento da família. Para Cohen e colaboradores (2004, p. 809), o "ambiente e entorno saudável incorporam a necessidade de equipamentos urbanos básicos como saneamento, espaços físicos limpos e estruturalmente adequados, bem como redes de apoio para se conseguir hábitos psicossociais sãos e seguros e isentos de violência”.

Constata-se, então, que das quatro famílias que foram visitadas, na primeira, seis pessoas moravam em dois cômodos; na segunda, quatro; na terceira, 10 pessoas residiam em um único espaço e a última família, com dois membros, habitava em dois cômodos. A estrutura física do domicílio poderá implicar nas condições de saúde da família, visto que o número de cômodos, por pessoa, é considerado insuficiente, pois para Wright e Leahey (2002) os fatores ambientais podem influenciar na dinâmica da família, repercutindo positivamente ou não em suas vidas e no processo saúde-doença.

De acordo com Cohen e colaboradores (2007), a habitação se constitui um espaço de construção e consolidação do desenvolvimento da saúde. A família tem na habitação seu principal espaço de sociabilidade, transformando-a em um espaço essencial, veículo da construção e desenvolvimento da saúde familiar. Neste estudo, a habitação se apresenta fragilizada pelas próprias condições ambientais e sociais apresentadas pelos moradores.

A partir da avaliação estrutural das famílias a violência vivida pelas mulheres mostrou-se contínua, cotidiana, expressa em diferentes modos, não só nas agressões físicas. Todas as mulheres apresentaram a mesma dificuldade em fazer esse reconhecimento e 
só o fazem quando pressentem risco de morte iminente, o que também pode não significar, necessariamente, uma ruptura com o agressor. Evidenciam isolamento social e político muito forte, o que pode contribuir para a reprodução de mecanismos mais complexos de violência, impedindo a mulher de manifestar-se de forma mais autônoma, a exemplo da Família 4.

Saffioti (1999) enfatiza que uma verdadeira política de combate à violência doméstica exige um trabalho em rede, englobando a colaboração intersetorial: polícia, ministério público, hospitais e profissionais da saúde, inclusive da área psicológica, da educação, do serviço social, além de grande número de abrigos muito bem gerenciados. Cabe ressaltar a necessidade da qualificação desses profissionais na utilização de mecanismos de enfrentamento do fenômeno (Tanaka e Oliveira, 2007; Paim, 2006).

Nesse contexto, a violência se perpetua em razão do imenso hiato entre a promulgação e a implementação de políticas, rede social de apoio e assistência efetiva para essas vítimas. Esta mulher ainda não é pensada e nem visualizada como sujeito que detém igualdade de direitos, índice significativo de participação no mercado de trabalho, e nem tampouco como um ser que se "equilibra" nos múltiplos papéis imputados pela historicidade sociocultural.

\section{Considerações Finais}

Diante do estudo, essas famílias apresentaram um perfil sociodemográfico que vai ao encontro da literatura e caracteriza os grupos que sobrevivem às iniqüidades sociais na luta para exercitar sua cidadania. Os fatores de risco para as violências contra a mulher não diferem dos já apresentados pelos estudiosos do tema.

Nesse sentido, é necessário que haja uma rede de cuidados que perpasse pelas políticas públicas em defesa da saúde da mulher (e famílias) e seja efetivada mediante ações intersetoriais, com autêntica formação interdisciplinar. Desse modo, vislumbra-se o desafio de se despertar e se mobilizar famílias para que se reconheçam cidadãs, no que concerne à dualidade dos direitos e deveres.

Nessa perspectiva, a sensibilidade e a aptidão para detectar fatores de risco e sinais de violência doméstica e coletiva contra a mulher, bem como articular ações de saúde em rede para a prevenção da violência e promoção da saúde, são dimensões inerentes à prática dos profissionais de saúde.

Por outro lado, a utilização do MCAF viabilizou uma maior compreensão das autoras acerca da estrutura das famílias trabalhadas, o que nos leva a sugerir sua aplicação pelos profissionais da Estratégia Saúde da Família.

\section{Referências}

BIASSOLI-ALVES, Z. M. M. Aproximações teóricas e conceituais de família e violência no final do século XX. Texto e Contexto Enfermagem, Florianópolis, v. 8, n. 2, p. 65-75, maio/ago. 1999.

BLAY, E. A. Violência contra a mulher e políticas públicas. Estudos Avançados, São Paulo, v. 17, n. 49, p. 87-98, set./dez. 2003.

BONIFAZ, R. G. V.; NAKANO, A. M. S. La violencia intrafamiliar, el uso de drogas en la pareja desde la perspectiva de la mujer mal-tratada. Revista LatinoAmericana de Enfermagem, São Paulo, v. 12, p. 433438, abr. 2004. Número especial.

BRASIL. Ministério da Saúde. Conselho Nacional de Saúde. Resolução nº 196, de 10 de outubro de 1996. Dispõe sobre diretrizes e normas técnicas regulamentadoras de pesquisas envolvendo seres humanos. Disponível em: <http://www.usjt.br/prppg/ coep/docs/resolucao_196.pdf >. Acesso em: og dez. 2007.

BRASIL. Ministério da Saúde. Secretaria de Vigilância em Saúde. Departamento de Análise de Situação de Saúde. Política Nacional de Redução da Morbimortalidade por Acidentes e Violência. 2. ed. Brasília, DF, 2005.

BRASIL. Ministério da Saúde. Atenção integral para mulheres e adolescentes em situação de violência doméstica e sexual. Brasília, DF, 2006a.

BRASIL. Ministério da Saúde. Secretaria de Vigilância em Saúde. Departamento de Análise de Situação em Saúde. Brasil 20o6: uma análise da desigualdade em saúde. Brasília, DF, 20o6b.

COHEN, S. C. et al. Habitação saudável no programa saúde da família (PSF): uma estratégia para as políticas públicas de saúde e ambiente. Ciência e Saúde Coletiva, Rio de Janeiro, v. 9, n. 3, p. 807-813, jun./set. 2004 . 
COHEN, S. C. et al. Habitação saudável e ambientes favoráveis à saúde como estratégia de promoção da saúde. Ciência e Saúde Coletiva, Rio de Janeiro, v. 12, n. 1, p. 191-198, 2007.

DAHLBERG, L. L.; KRUG, E. G. Violência: um problema global de saúde pública. Ciência e Saúde Coletiva, Rio de Janeiro, v. 11, p. 1163-1178, 2006. Suplemento.

DESLANDES, S. F.; GOMES, R.; SILVA, C. M.F.P. A caracterização dos casos de violência doméstica contra a mulher atendida em dois hospitais públicos do Rio de Janeiro. Cadernos de Saúde Pública, Rio de Janeiro, v. 16, n. 1, p. 129-137, jan./mar. 2000.

DINIZ, R. C. M.; FRAGA, M. N. O. O contexto social e epidemiológico dos moradores assentados em área de manguezal. Revista Brasileira em Promoção da Saúde, Fortaleza, v. 18, n. 2, p. 98-104, abr./jun. 2005.

GOMES, M. A.; PEREIRA, M. L. D. Família em situação de vulnerabilidade social: uma questão de políticas públicas. Ciência e Saúde Coletiva, Rio de Janeiro, v. 10, n. 2, p. 357-363, abr./jun. 2005.

GOMES, R.; MINAYO, M. C. de S.; SILVA, C. F. R. da. Violência contra a mulher: uma questão transnacional e transcultural das relações de gênero. In: BRASIL. Ministério da Saúde. Secretaria de Vigilância em Saúde. Impacto da violência na saúde dos brasileiros. Brasília, DF, 2005. p. 117-140.

KRUG, E. G. et al. World report on violence and health. Geneve: World Health Organization, 2002.

LANDIM, F. L. P. et al. Comunidade mutirante: características familiares e sua rede de suporte social. Revista Brasileira em Promoção da Saúde, Fortaleza, v. 17, n. 4, p. 177-186, out./dez. 2004.

LEOPARDI, M. T. et al. Metodologia da pesquisa na saúde. 2. ed. Florianópolis: UFSC, 2002.

MARINHEIRO, A. L. V.; VIEIRA, E. M.; SOUZA, L. Prevalência de violência contra a mulher. Revista de Saúde Pública, São Paulo, v. 4o, n. 4, p. 6o4-610, ago. 2006.
MARTINS, C. S. et al. A dinâmica familiar na visão de pais e filhos envolvidos na violência doméstica contra crianças e adolescentes. Revista LatinoAmericana de Enfermagem, Ribeirão Preto, v. 15, n. 5 , set./out. 2007. Disponível em: <http://www.scielo.br/ pdfrlae/v15n5pt_v15n5ao1.pdf >. Acesso em: $12 \mathrm{dez}$. 2007.

MENEGHEL, S. N. et al. Cotidiano ritualizado: grupos de mulheres no enfrentamento à violência de gênero.Ciência e Saúde Coletiva, Rio de Janeiro, v. 10, n. 1, p.111-118, jan./mar. 2003.

MINAYO, M. C. de S. Violência: um problema para saúde dos brasileiros. In: BRASIL, Ministério da Saúde. Secretaria de vigilância em saúde. Impacto da violência na saúde dos brasileiros. Brasília, DF, 2005. p. 9-41.

MIOTO, R. C. As famílias de hoje. Texto e Contexto Enfermagem, Florianópolis, v. 8, n. 2, p. 211-219, maio/ ago.1999.

NAÇÕES UNIDAS. Centro para o Desenvolvimento Social e Assuntos Humanitários - Gabinete das Nações Unidas de Viena. Estratégias de combate à violência doméstica: manual de recursos. Lisboa: Ministério da Saúde, Direcção-Geral da Saúde, 2003.

OLIVEIRA, E. N. Pancada de amor dói e adoece: violência física contra mulheres. Sobral: Ed. UVA, 2007 .

PAIM, J. S. Eqüidade e reforma em sistemas de serviços de saúde: o caso do SUS. Saúde e Sociedade, São Paulo, v. 15, n. 2, p. 34-46, 2006

PEÇANHA, D. L. Instrumento de diagnóstico sistêmico: contribuições ao estudo de família com problemas de violência. Texto e Contexto Enfermagem, Florianópolis, v. 8, n. 2, p. 431-435, maio/ ago. 1999 .

ROQUE, E. M. S. T.; FERRIANI, M. G. C. Desvendando a violência doméstica contra crianças e adolescentes sob a ótica dos operadores do direito na comarca de Jardinópolis-SP. Revista Latino-Americana de Enfermagem, São Paulo, v. 1o, n. 3, p. 334-344, maio/ jun. 2002. 
SABROZA, A. R. et al. Perfil sócio-demográfico e psicossocial de puérperas adolescentes do Município do Rio de Janeiro, Brasil - 1999-2001. Cadernos de Saúde Pública, Rio de Janeiro, v. 20, p. S83-S91, 2004. Suplemento 1.

SALES, L. M. M.; LEITE, S. R. O direito fundamental de propriedade e a Comunidade do Dendê. Pensar, Fortaleza, v. 10, n. 10, p. 73-81, fev. 2005.

SAFFIOTI, H. I. B. Gênero e patriarcado: violência contra as mulheres. São Paulo: PUC, 1999.

SANCHEZ, Z. V. D. M.; NAPPO, S. A. A religiosidade, a espiritualidade e o consumo de drogas. Revista de Psiquiatria Clínica-, São Paulo, v.34, supl.1, p.73-81, volume, número, paginação, 2007. Disponível em:< http://www.hcnet.usp.br/ipq/revista/vol34/s1/ 73.html>. Acesso em: 30 maio 2008.
SCHRAIBER, L. B. et al. A violência dói e não é direito: a violência contra a mulher, a saúde e os direitos humanos. São Paulo: UNESP, 2005.

SILVA, I. V. Violência contra mulheres: a experiência de usuárias de um serviço de urgência e emergência de Salvador, Bahia, Brasil. Cadernos de Saúde Pública, Rio de Janeiro, v. 19, p. 263-272, 2003.

TANAKA, O. Y.; OLIVEIRA, V. E. Reforma(s) e estruturação do Sistema de Saúde Britânico: lições para o SUS. Saúde e Sociedade, São Paulo, v. 16, n.

1, p. 7-17, 2007.

WRIGHT, L. M.; LEAHEY, M. Enfermeiras e famílias: um guia para avaliação e intervenção na família. 3 . ed. São Paulo: Roca, 2002.

XIMENES, L. B. et al. A influência dos fatores familiares e escolares no processo saúde-doença da criança na primeira infância. Acta Scientiarum, Maringá, v. 26, n. 1, p. 223-230, jan./jun. 2004. 